\title{
Evidence-based conservation: predator-proof bomas protect livestock and lions
}

\author{
Laly L. Lichtenfeld • Charles Trout $\cdot$ Elvis L. Kisimir
}

Received: 1 October 2014/Accepted: 15 October 2014/Published online: 2 December 2014

(C) The Author(s) 2014. This article is published with open access at Springerlink.com

\begin{abstract}
African lions (Panthera leo) are in decline across many parts of the continent with retaliatory killing of lions for attacks on livestock being an important cause. In East Africa, projects are fortifying bomas to reduce large carnivore conflicts with the specific goal of preventing the indiscriminate killing of lions. A lack of evidence-based studies evaluating the impact of these efforts means their efficacy for lion conservation is not yet scientifically verifiable. We evaluated fortified bomas by comparing large carnivore attack rates at 84 unprotected bomas and 62 fortified bomas called Living Walls. The latter were $99.9 \%$ successful in preventing nighttime carnivore attacks over 1,790 boma-months. Following Living Wall installation, there were no lion deaths at fortified bomas. Our results demonstrate the importance of predator-proof enclosures as a tool for lion conservation across the continent in areas where they inhabit human-and livestock-dominated landscapes. This study also contributes more broadly by highlighting the importance of scientifically evaluating conservation efforts.
\end{abstract}

Keywords African lion - Maasai - Large carnivores - Community-based conservation · Tanzania $\cdot$ East Africa

\section{Introduction}

In conservation, there is much discussion of problems, little about possible solutions, and even fewer assessments of whether solutions are effective or not (Sutherland et al. 2004).

Communicated by Stuart Pimm.

L. L. Lichtenfeld $(\bowtie) \cdot$ C. Trout

African People \& Wildlife Fund, P.O. Box 624, Bernardsville, NJ 07924, USA

e-mail: lichtenfeld@afrpw.org

L. L. Lichtenfeld · C. Trout · E. L. Kisimir

Tanzania People \& Wildlife Fund, Box 11306, Arusha, Tanzania

L. L. Lichtenfeld

Yale School of Forestry and Environmental Studies, 195 Prospect St., New Haven, CT 06511, USA 
Lions (Panthera leo) are declining across many parts of Africa (Riggio et al. 2013) with retaliatory killing of lions for attacks on livestock being an important cause (Species Survival Commission Cat Specialist Group 2006). Large terrestrial predators worldwide suffer similar problems (Clark et al. 1996; Weber and Rabinowitz 1996; Gittleman et al. 2001; Ray et al. 2005), risking local extirpation where they come into conflict with human communities (Gittleman et al. 2001). African lions are typical. Beyond protected area boundaries, they frequently kill cattle and occasional small stock (i.e. sheep and goats, referred herein as shoats; Kolowski and Holekamp 2006). The loss of culturally and economically valuable commodities motivates retaliatory killing among livestock owners and herdsmen (Hazzah et al. 2009). Hence, lion mortality is much higher for individuals that kill livestock (Woodroffe and Frank 2005). Vigilant livestock husbandry methods can decrease large carnivore-livestock conflicts (Ogada et al. 2003). In East Africa, projects are fortifying traditional livestock corrals (called bomas) to reduce large carnivore conflicts with the specific conservation goal of preventing the indiscriminate poisoning, spearing and shooting of lions. While all large carnivores-lions, leopards (Panthera pardus), hyenas (Hyaenidae), wild dogs (Lycaon pictus) and cheetahs (Acinonyx jubatus) —attack livestock, lions are typically the focus of retaliatory efforts (Lichtenfeld 2005; Kissui 2008), hence the targeted use of the boma fortification strategy as a lion conservation measure. However, a lack of evidence-based studies evaluating the impact of these efforts on lion mortality means their efficacy for lion conservation is not yet scientifically verifiable. More specifically, little empirical evidence is available to demonstrate the impact of systematic measures to improve livestock husbandry on depredation rates and the retaliatory killing of lions. Here, we ask how effective are measures to fortify bomas against attacks by large carnivores?

\section{Materials and methods}

Just east of Tarangire National Park on the Maasai Steppe of northern Tanzania, we monitored 146 permanent bomas in the community of Loibor Siret-a total land holding of $550 \mathrm{~km}^{2}$ - for large carnivore attacks over 9,296 boma-months (Fig. 1a). Our monitoring period ran from September 2003 to August 2013. (We did no monitoring between Jan 2005-Feb 2006 and Jan 2009-Feb 2010.) A trained, local Maasai community member verified all reports of depredation at three boma types (permanent-ngijiji, immigrantuhamiaje and seasonal-ronjo) and at pasture by collecting a detailed record of each account, a GPS location and photographs of the incident where possible. In 2011, a second trained community member followed the same protocol in the neighboring village of Kimotorok (where the distance between the two village centers is just $30 \mathrm{~km}$ ). We verified a total of 274 attacks (112 at the boma, 162 at pasture) where 68 separate attacks occurred on the permanent monitored bomas (ngijiji) included in this study (i.e. additional attacks occurred at immigrant (uhamiaje) and seasonal bomas (ronjo) in Loibor Siret as well as bomas in Kimotorok). We considered these accounts to represent the minimum number of attacks that occurred over the monitoring period, assuming not all attacks were likely to be accounted for (e.g. due to lack of reporting, illness, travel, etc.).

Typically, the Maasai construct their traditional bomas by piling up thorny branches, a time-consuming activity that requires constant upkeep as the harvested thorn dries and degrades. Livestock owners construct traditional bomas in a circular shape, using the dried thorn as the primary construction material for both the walls and the gates of the boma. With the increasing permanence of households or ngijiji (as evidenced by brick and cement 
Fig. 1 a Loibor Siret village land in relation to Tarangire National Park and neighboring communities. Created using Google Earth imagery and software (2014 Google; 2014 CNES/Spot Image; 2014 DigitalGlobe; US Dept of State Geographer) b distribution of 146 bomas in Loibor Siret village including 62 bomas fortified as Living Walls. Created using Google Earth imagery and software (2014 Google; 2014 CNES/Spot Image; 2014 DigitalGlobe; US Dept of State Geographer)
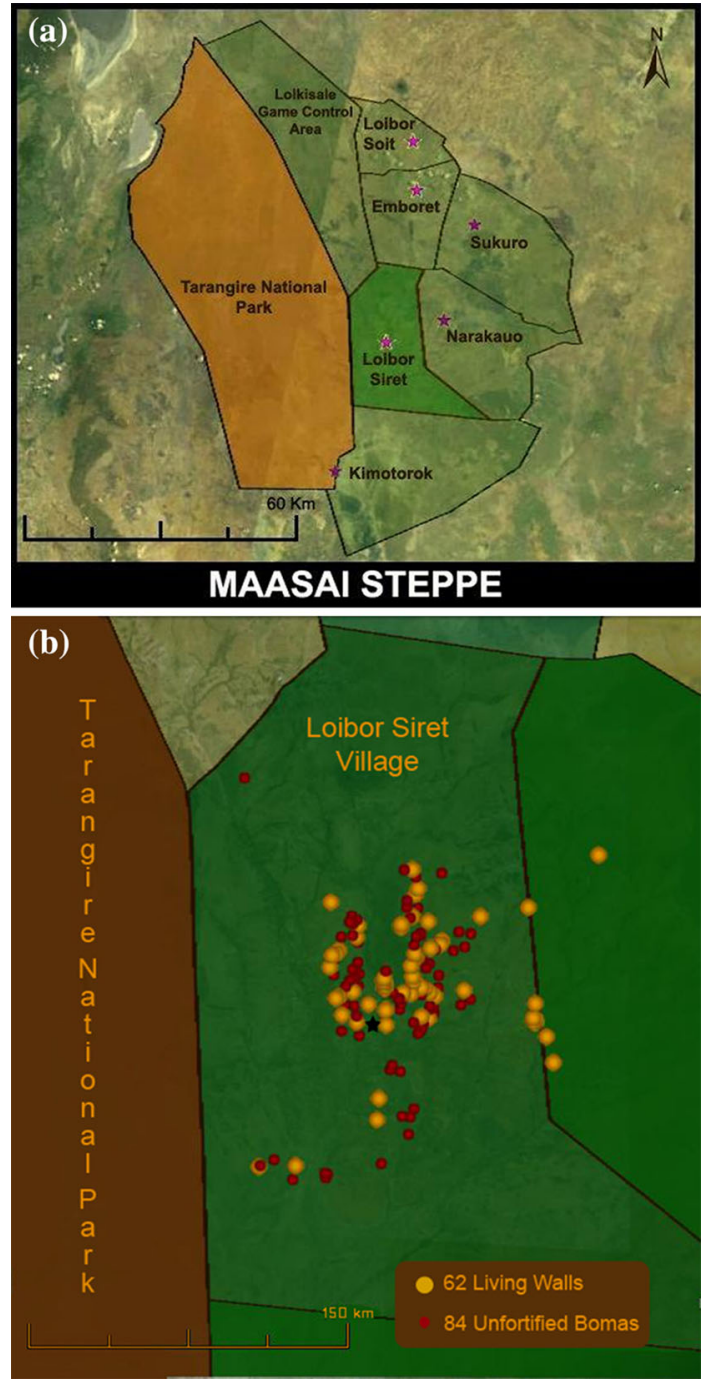

structures alongside the bomas; the oldest boma in our location was established in 1972, mean year of boma establishment was 2003; note the concentration of households in an area of approximately $70 \mathrm{~km}^{2}$, Fig. 1b), sourcing thorn is often difficult, requiring families to travel greater distances to find suitable materials. Therefore, characteristics of traditional bomas often include holes and/or low fencing which make it relatively easy for a large carnivore to penetrate the boma wall. Such traditional bomas represented the control (unfortified) bomas described in this study (Fig. 2).

In order to eliminate the weaknesses of traditional bomas (i.e. holes, low fencing, use of permeable/degradable materials), a number of fortified fencing techniques have been developed (e.g. reinforced acacia/thorn bomas, stone bomas, Living Walls, etc.; Begg and Kushnir 2010). Between 2008 and 2013, we fortified 62 of the 146 traditional bomas in Loibor Siret with Living Walls-environmentally-friendly, predator-proof enclosures that 


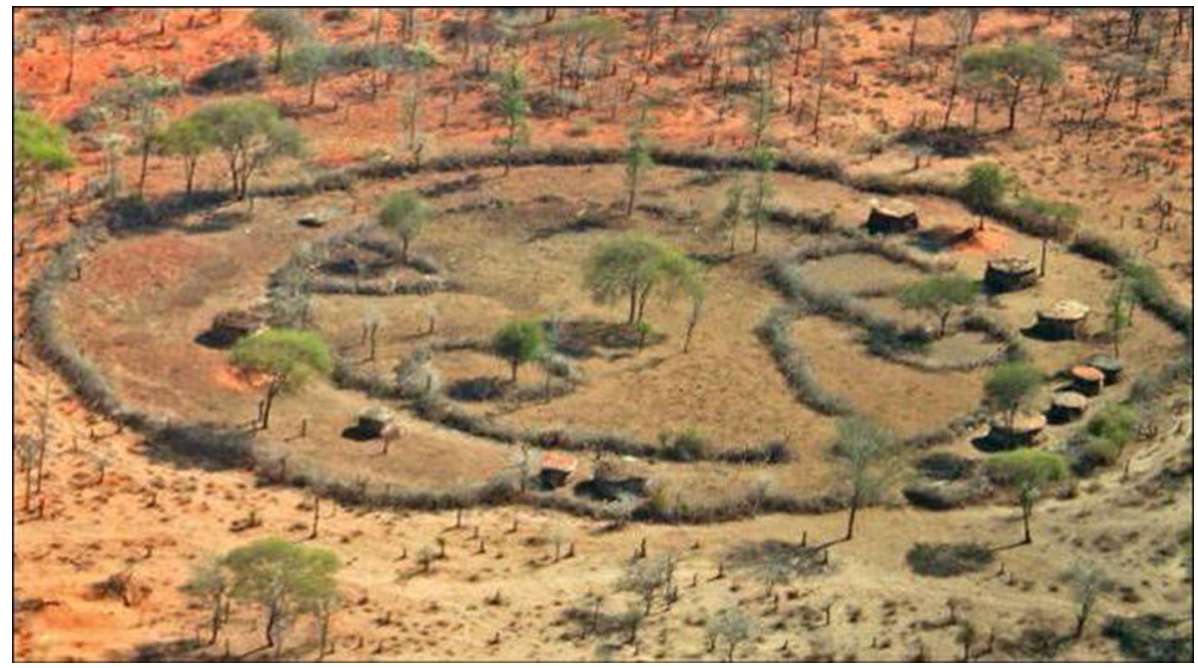

Fig. 2 Aerial view of a traditional, Maasai boma; inner, thorn ring represents the livestock enclosure

combine fast-growing, thorny trees as fence posts with chain link fencing (Fig. 3). By encircling the original boma with chain link fencing, we eliminated all holes that are typically evident in traditional bomas and strengthened the fence. Meanwhile, by planting Commiphora sp. as fence posts at $0.5 \mathrm{~m}$ intervals, we added height to the fence (as compared to traditional bomas or other fortified fences), as the trees continued to grow and fill in around the top of the chain link fencing. The use of live trees as fence posts also had the added benefit of reducing the costs and maintenance requirements associated with other fortified fencing techniques that would require the repeated purchase of wooden (not rot or termite-resistant) or expensive metal poles to hold the chain link. It is easy to limb Commiphora sp. in the bush; this process does not harm the parent tree. Livestock owners requesting a Living Wall harvest and plant the Commiphora prior to our team's delivery of chain link fencing. The average cost of the chain link for a Living Wall in the study area is $\$ 500$ (at $\$ 4$ per meter, boma circumference varies across Maasailand; L. L., C. T., \& E. K., unpublished data). This is cost-shared; the livestock owner pays $25 \%$ of the total costs of the chain link fencing over an individually-tailored repayment period. Our team contributes labor and other materials (equipment, nails, etc.) during the affixation of the Commiphora to the chain-link fencing in order to ensure proper and consistent installation across all Living Walls. We monitored the Living Walls for 1,790 boma-months, each from their individual installation date through to August 2013. Significant differences between fortified and unfortified bomas were tested using Chi square analyses.

\section{Results}

Of 68 recorded large carnivore attacks on 44 permanent bomas, hyenas accounted for $52 \%$ followed by lions (32\%), leopards $(15 \%)$ and jackals $(1 \%)$. Large carnivores attacked a total of 115 livestock units (33 cattle, 77 shoats, and five donkeys), killing 86 animals and wounding 29. We assessed the value of damages using the 2012 average market value for 


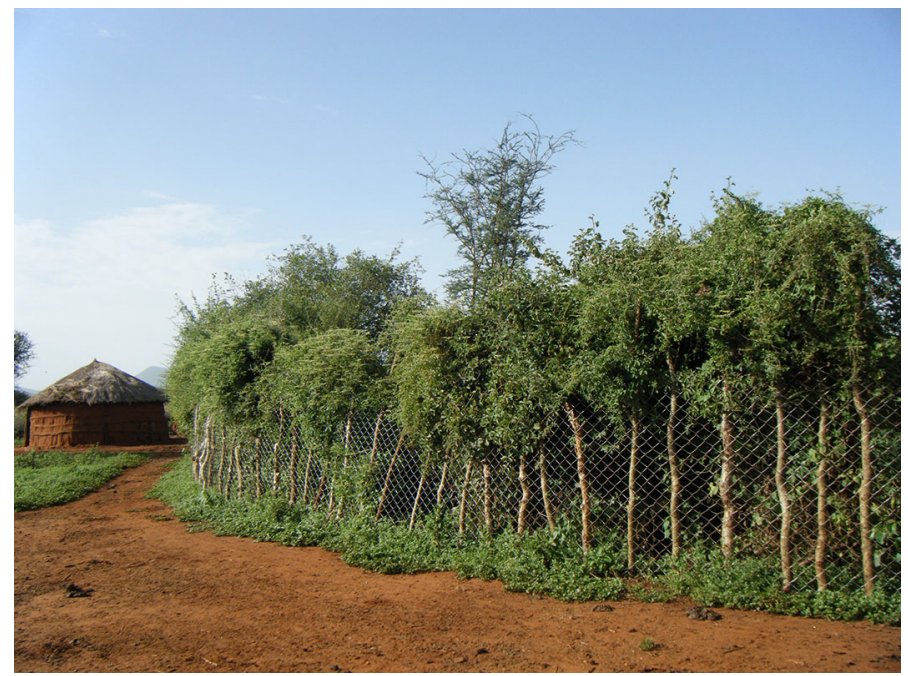

Fig. 3 A Living Wall

cattle (\$450), shoats $(\$ 50)$ and donkeys $(\$ 200)$, converted at a rate of 1,550 Tanzanian Shillings to 1 US Dollar. This amounted to $\$ 19,700$ in damages (assuming wounded animals died later or lost their value due to injuries). Lions were responsible for $64 \%$ of all predator-induced financial loss or $\$ 12,550$ due to their greater likelihood to kill cattle. All events took place at night except for the one jackal attack that occurred during the day. $66 \%$ of attacks occurred during the rainy (November-April; $\mathrm{n}=37$ ) and intermediate seasons (May-June; $\mathrm{n}=8$ ), coinciding with the seasonal movement of wildlife outside of Tarangire National Park.

Our experimental design meant that we had several comparisons in terms of the impact of fortified bomas. First, there were two sets of bomas: the same set of bomas before and after fortification with Living Walls plus another set of bomas that were never fortified. We fortified bomas on the basis of their past record of attacks, protecting those bomas most likely to be attacked. The pre-fortification attack rate for eventually protected bomas was 0.012 attacks per boma per month (27 attacks over 2,185 boma-months). From this, we expected 22.12 attacks on the 62 Living Walls during the subsequent 1,790 fortified bomamonths. We observed only two, a result significant at $p=0.00000005\left(\chi^{2}\right)$. The never fortified bomas suffered 39 attacks over 5,321 boma-months, a lower attack rate of 0.007 attacks per boma-month. Now, the bomas we eventually protected might have initially suffered more attacks simply by chance. If so, the overall estimate of attack rate for all unfortified bomas is 0.009 attacks per boma per month (66 attacks over 7,506 bomamonths). The expected number of attacks on fortified bomas drops to 15.74 , but the minimal number of attacks at Living Walls is still highly significant $\left(p=0.0005, \chi^{2}\right)$.

The next set of comparisons recognized that attacks may have been contingent in space (as we have just shown) and also in time. Assuming statistical independence and so a Poisson distribution, we expected only $0.004 \%$ of attacks to be at the same boma. In fact, 24 of 66 attacks were such repeats. So, we then treated attacks at the same boma as the unit of analysis - an "attack event". The frequency was 0.006 attack events per boma per month (42 attacks and repeated attacks over 7,506 boma-months). We expected 10.02 
attack events in the 1,790 fortified boma months and 12.29 attack events if we considered only the attack events of those bomas that were eventually fortified. Again, the minimal number of attacks was significant at $p=0.002$ and $p=0.0003$ respectively ( $\chi^{2}$ tests).

We employed two additional comparisons between fortified and unfortified bomas, each with obvious advantages and disadvantages. First, for attacked bomas, we compared the same individual bomas before and after protection with Living Walls. Inevitably, these comparisons were for different periods with boma protection in later years. Second, we compared pairs of bomas: one protected boma with another unprotected boma situated as close by as possible. Not only were the bomas different, but the timing reflected the period after fortification of the Living Wall set.

Table 1 shows the attacks, the numbers and months of the attacks, the number of quiet months (without attacks), the number of months when we did not record data, and months when bomas were protected and not attacked and when they were. Thus, across all the eventually fortified bomas, in March there were six attacks, while 66 months were quiet when the bomas were unprotected. In the 48 months after protection, we would expect 4 attacks, but none occurred. Summed over all months for which we can make comparisons, we expected 17.56 attacks, but only observed two. A $\chi^{2}$ test is highly significant $(p=0.0002)$. We then compared 27 unprotected bomas with nearby bomas that were protected. These comparisons were mostly in 2012 and 2011, with some in 2010. Only one unprotected boma was attacked, while two protected ones were attacked, in 822 boma months.

In order to test the impact of fortified bomas on large carnivore behavioral ecology (specifically the possibility of behavioral shifts leading to increasing pasture depredation or attacks on unfortified bomas), we analyzed annual depredation rates for all boma and pasture attacks (Table 2). No increase in pasture depredation in Loibor Siret is evident as a result of the treatment phase-installation of Living Walls. Similarly, there is no shift in depredation patterns to unfortified bomas. Overall, boma depredation rates in Loibor Siret declined by $90 \%$. Meanwhile, pasture depredation rates declined by only $32 \%$ over the same time periods (pre-treatment vs. treatment).

\section{Discussion}

Before our interventions, large carnivores carried out approximately 50 attacks on livestock per community each year. Retaliation against livestock depredation killed 6-7 lions per community per year on the Maasai Steppe. This equated to an annual loss of 72-84 lions across 12 communities (Lichtenfeld 2005; Kissui 2008). Significantly, no retaliatory killing of lions, leopards or hyenas occurred at fortified bomas despite the continued presence of these species in Loibor Siret (L. L., C. T., \& D. Minja, unpublished data). On the other hand, five lions died from poisoning in Loibor Siret after killing livestock at an unfortified boma in May 2013.

Following Living Wall installation, we recorded only two incidences of livestock depredation at fortified bomas. Importantly in both cases, the gate of the Living Wall was not properly constructed, and a leopard was able to enter through the gate and kill shoats. Following these incidences, we checked and reconstructed all Living Wall gates where required.

Of the 44 bomas attacked over the study period, livestock damages cost $\$ 19,700$ or approximately $\$ 448$ per attacked boma. Given that we conservatively assumed no cost of establishing and maintaining unfortified bomas (due to the difficulty of financially equating 
Table 1 Seasonal and expected attack rates for attacked bomas (before and after protection)

\begin{tabular}{|c|c|c|c|c|c|c|c|c|c|c|c|c|}
\hline \multirow[t]{2}{*}{ Period } & \multicolumn{12}{|l|}{ Month } \\
\hline & Sept & Oct & Nov & Dec & Jan & Feb & Mar & Apr & May & Jun & Jul & Aug \\
\hline Attacks & 3 & 0 & 2 & 1 & 2 & 2 & 6 & 3 & 1 & 1 & 3 & 2 \\
\hline $\begin{array}{r}\text { Quiet (no } \\
\text { attacks) }\end{array}$ & 78 & 76 & 69 & 70 & 43 & 44 & 66 & 69 & 72 & 72 & 71 & 71 \\
\hline Not recorded & 55 & 55 & 55 & 54 & 81 & 80 & 50 & 50 & 49 & 49 & 48 & 48 \\
\hline $\begin{array}{l}\text { Protected-no } \\
\text { attacks }\end{array}$ & 34 & 39 & 44 & 45 & 44 & 44 & 48 & 48 & 48 & 48 & 48 & 47 \\
\hline $\begin{array}{c}\text { Protected- } \\
\text { attacks }\end{array}$ & 0 & 0 & 0 & 0 & 0 & 0 & 0 & 0 & 0 & 0 & 0 & 2 \\
\hline $\begin{array}{l}\text { Seasonal } \\
\text { attack rate }\end{array}$ & 0.037 & 0 & 0.028 & 0.014 & 0.044 & 0.043 & 0.083 & 0.042 & 0.014 & 0.014 & 0.041 & 0.027 \\
\hline $\begin{array}{l}\text { Expected } \\
\text { attacks (n) }\end{array}$ & 1.26 & 0.00 & 1.24 & 0.63 & 1.96 & 1.91 & 4.00 & 2.00 & 0.66 & 0.66 & 1.95 & 1.29 \\
\hline
\end{tabular}

Table 2 Annual depredation rates according to phase in the focal village of Loibor Siret and its neighbor, Kimotorok

\begin{tabular}{lclllll}
\hline Location & Year & Phase & $\begin{array}{l}\text { Total } \\
\text { attacks (n) }\end{array}$ & & \multicolumn{2}{l}{\begin{tabular}{l} 
Annual depredation rates \\
\cline { 3 - 6 }
\end{tabular}} \\
& & & $\begin{array}{l}\text { Combined } \\
\text { (average \# attacks/month) }\end{array}$ & Pasture \\
\hline & 2004 & Pre-treatment & 33 & 2.75 & 0.83 & 1.92 \\
& $2006^{\mathrm{a}}$ & Pre-treatment & 52 & 5.20 & 2.60 & 2.60 \\
& 2007 & Pre-treatment & 56 & 4.67 & 2.33 & 2.33 \\
& 2008 & Pre-treatment & 45 & 3.75 & 1.83 & 1.92 \\
& $2010^{\mathrm{a}}$ & Treatment & 17 & 1.70 & 0.30 & 1.40 \\
Kimotorok & 2011 & Treatment & 19 & 1.58 & 0.17 & 1.42 \\
& 2012 & Treatment & 22 & 1.83 & 0.17 & 1.67 \\
& 2011 & No treatment & 30 & 2.50 & 1.58 & 0.92 \\
\hline
\end{tabular}

${ }^{a}$ Only 10 months of monitoring; all other years include 12 months of monitoring

time and effort and despite the substantial need to replenish dried thorn every few months), Living Walls appear highly cost effective since the average livestock owner's one-time financial contribution was $\$ 125$ and little maintenance is required due to the live nature of the fence posts (as opposed to wooden fence posts that may rot or be eaten by termites). Living Walls were immediately successful at deterring large carnivores as indicated by the minimal penetration rate (99.9\% successful over 1,790 boma-months). Commercial data indicate that the chain link will last at least 20 years. Thus our results suggest that Living Walls will have an impact for that length at least and, if the living component becomes thick and thorny enough, for even longer. Finally, by planting trees as fence posts, Living Walls have the added benefit of contributing to reforestation/climate change adaptation strategies.

Overall, we found strikingly few attacks in later years of the analysis. There are at least two explanations. The first is for reasons unconnected to protecting bomas, large carnivore 
attacks have, for reasons we do not understand, declined. Second, we deliberately selected those bomas with high attack rates to protect first (see the higher pre-fortification attack rate for eventually protected bomas demonstrated in the results). By protecting these particularly vulnerable bomas, we think it likely that other bomas have benefited from the reduced large carnivore activity and there has been a general reduction in attack rates for this reason.

Of course, it is likely that large carnivore numbers declined over the nearly 10 year monitoring period. However, if this were alone to explain the decline in boma depredation, then we would expect an equivalent decline in pasture depredation rates given the removal of large carnivores from the system. This was not reflected in the data (refer to Table 2). Furthermore, boma attacks in the neighboring village of Kimotorok (no treatment) continued to occur at higher (though not elevated) rates, again ruling out the possibility that a decline in large carnivore numbers is solely responsible for the decline in depredation rates.

We experienced no conditioning of large carnivores to the Living Walls over an average installation period of 29 months (and up to 58 months) or switching to elevated pasture depredation rates or attacks on unfortified bomas. This indicates Living Walls have a longterm effect on large carnivore conflict prevention. Attacking a boma represents a learned behavior (Woodroffe and Frank 2005). By breaking this learning cycle, we would expect (and witnessed) decreases in boma depredation rates at unfortified bomas. Notably, our fortification strategy emphasized the construction of a large number of Living Walls within a small, geographic area (approximately $70 \mathrm{~km}^{2}$, see Fig. 1b), rather than spreading them widely across the landscape which might have diluted this positive impact on neighboring, unfortified bomas. It is also possible that fewer livestock carcasses in the vicinity of permanent bomas had the effect of decreasing large carnivore activity in the area. Finally, we also experienced the increasing likelihood of livestock owners to call our Living Wall team for help following large carnivore attacks at pasture rather than taking measures into their own hands. This suggests the boma fortification project also had an impact on diffusing tensions at a broader scale.

This work provides an evidence-based account of the significant impact predator-proof bomas have on reducing livestock depredation and the retaliatory killing of lions. Efforts to increase the fortification of bomas through various designs (e.g. Living Walls, traditional designs, mobile units, etc.) should receive widespread support from the conservation community as a proven method for contributing to the conservation of this highly threatened big cat as well as other globally significant large carnivores such as leopards and hyenas. Although our study specifically pertains to African large carnivores, our results have broad significance to the conservation community that is taking increasing measures to mitigate human-wildlife conflicts. We demonstrate the importance of scientifically measuring the outcome of conservation interventions as a means to improve our collective impact, particularly where multiple projects are utilizing similar strategies as in the case of predator-proofing bomas. This will not only increase our ability to employ successful conservation measures across a broad scale, but it will also improve society's likelihood to invest in wildlife conservation.

Acknowledgments We would like to thank the Tanzania Wildlife Research Institute and the Wildlife Division of the Ministry of Natural Resources and Tourism for their support and assistance during the implementation of this conservation program, and the local communities of the Maasai Steppe for their assistance and participation in monitoring conflict. The authors would like to thank AWELY-Wildlife \& People and the Mohammed Bin Zayed Species Conservation Fund for supporting the establishment of pilot Living Walls. Major scale-up support for Living Wall installations and monitoring were provided by the 
National Geographic Big Cats Initiative, as well as the Regina Bauer Frankenberg Foundation, the Disney Worldwide Conservation Fund, the Charles Engelhard Foundation and individual contributors to the project. Sponsors had no involvement in study design, analyses or manuscript preparation. L. L. wrote the main manuscript text and C. T. prepared Fig. 1. E. K. carried out data collection and managed community assistants during a large portion of the monitoring period.

Conflict of interest The authors declare that they have no conflict of interest.

Open Access This article is distributed under the terms of the Creative Commons Attribution License which permits any use, distribution, and reproduction in any medium, provided the original author(s) and the source are credited.

\section{References}

Begg, C, Kushnir H (ed) (2010) Human-lion conflict toolkit. Ratel Trust, Cape Town, South Africa. Available from http://www.rateltrust.org/library_files/Human-Lion\%20Conflict\%20Toolkit.pdf. Accessed June 282014

Clark TW, Curlee AP, Reading RP (1996) Crafting effective solutions to the large carnivore conservation problem. Conserv Biol 10:940-948

Gittleman JL, Funk SM, Macdonald DW, Wayne RK (eds) (2001) Carnivore conservation. Cambridge University Press, New York

Hazzah L, Mulder MB, Frank LG (2009) Lions and warriors: social factors underlying declining African lion populations and the effect of incentive-based management in Kenya. Biol Conserv 144:2428-2437

Kissui BM (2008) Livestock predation by lions, leopards, spotted hyenas and their vulnerability to retaliatory killing in the Maasai Steppe, Tanzania. Anim Conserv 11:422-432

Kolowski JM, Holekamp KE (2006) Spatial, temporal, and physical characteristics of livestock depredations by large carnivores along a Kenyan reserve border. Biol Conserv 128:529-541

Lichtenfeld LL (2005) Our shared kingdom at risk: human-lion relationships in the 21st century. PhD Dissertation, Yale University, CT

Ogada MO, Woodroffe R, Oguge NO, Frank LG (2003) Limiting depredation by African carnivores: the role of livestock husbandry. Conserv Biol 17:1-10

Ray J, Redford K, Steneck R, Berger J (eds) (2005) Large carnivores and the conservation of biodiversity. Island Press, Chicago

Riggio J et al (2013) The size of savannah Africa: a lion's (panthera leo) view. Biodivers Conserv 22:17-35

Species Survival Commission Cat Specialist Group (2006) Regional conservation strategy for the lion panthera leo in eastern and southern Africa. International Union for Conservation of Nature (IUCN), Gland

Sutherland WJ, Pullin AS, Dolman PM, Knight TM (2004) The need for evidence-based conservation. Trends Ecol Evol 19:305-308

Weber W, Rabinowitz A (1996) A global perspective on large carnivore conservation. Conserv Biol 10:1046-1054

Woodroffe R, Frank LG (2005) Lethal control of African lions (Panthera leo): local and regional population impacts. Anim Conserv 8:91-98 